\title{
||||||||||||||||||||||||||||||||||||||||||||||||||||||||||||||||||.
}

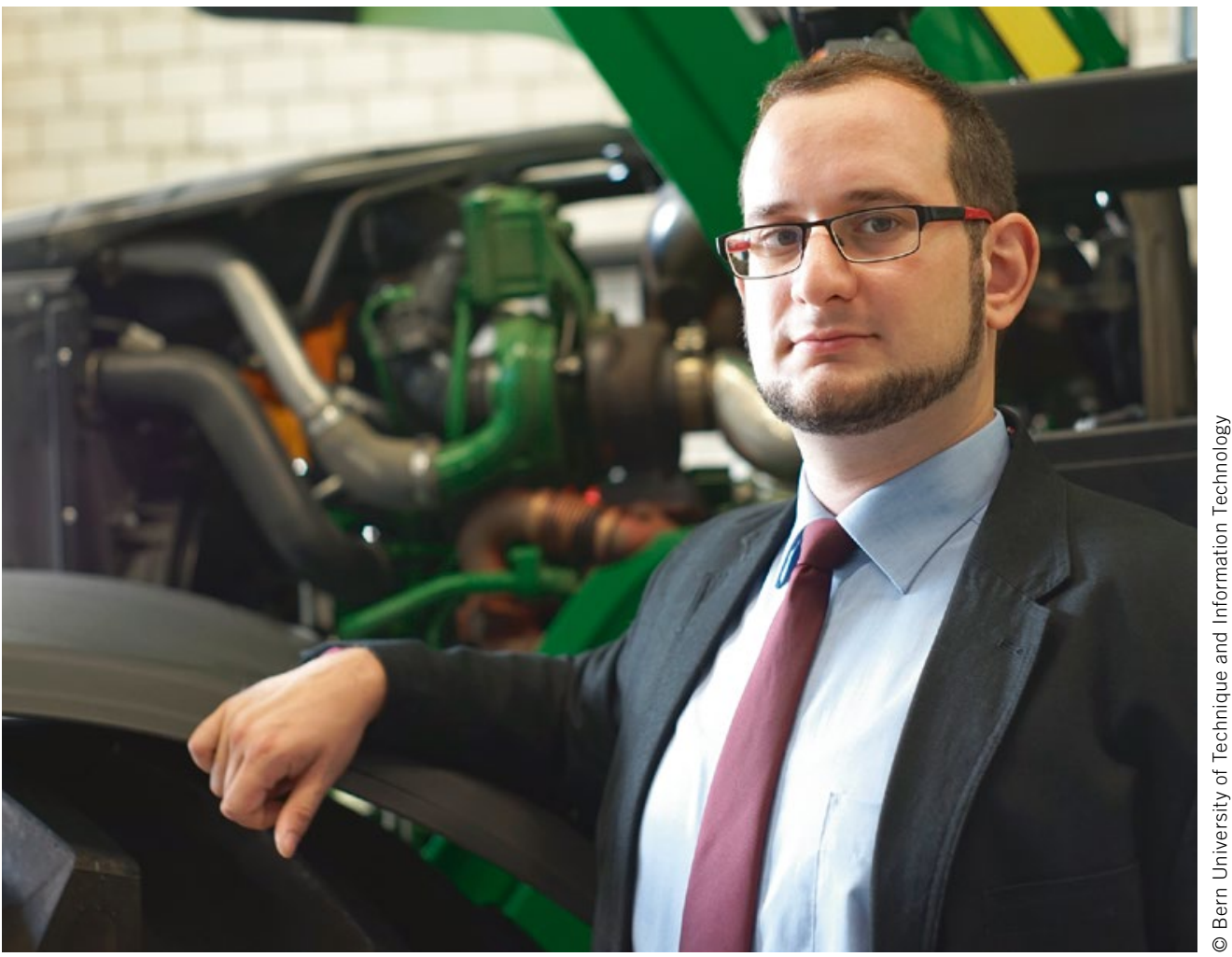

Prof. Danilo Engelmann

Professor for IC-Engines and Thermodynamics and Head of the Exhaust Emission Control Laboratory $(\mathrm{AFHB})$ and the $\mathrm{IC}$-Engine Laboratory of the Bern University of Technique and Information Technology (Switzerland)

\section{Drives in Flux}

Initially, in 1893 , there was a statement that the development of agricultural machinery was completed, but all mobile machines have constantly evolved towards greater efficiency and functionality. For the drives of mobile machines, there were constantly new challenges and changing boundary conditions. Until recently, the EU Stage V emission stage was the focus of the engine development of the manufactures. Here one has found adequate technical solution in the meantime. Thus, an important step has been taken to enable mobile machines to emit even less emissions. New challenges in the field of exhaust gas aftertreatment are today a preferably integrated design for exhaust elements to spare the limited design space on the machines, but even here good solutions are emerging, for example a combined filter unit for diesel particles and nitric oxide reduction (SCR on DPF). In order to reduce not only pollutants but also anthropogenic $\mathrm{CO}_{2}$, the European construction and agricultural machinery associations have defined four important pillars for $\mathrm{CO}_{2}$ reduction. The pillars of machine and process efficiency, improving handling and the use of alternative energy sources. Today, the interdisciplinary cooperation of drive developers must not only consider the human-machine factors but also the working process and the surrounding infrastructure if the developer wants to further reduce emissions, especially with a view to the use of promising alternative energy sources.

Electric machines in the powertrain have been known for a long time in mobile machines and offer many advantages and degrees of freedom in the drivetrain and in propulsion systems on implements. However, the energy density of electrical storage is too low especially at high continuous power. Hybrid structures can here combine the advantages of high energy density of the diesel with the functionality of the electrical components. Another promising option is the use of regenerative fuel to close the $\mathrm{CO}_{2}$ cycle, then no additional $\mathrm{CO}_{2}$ is produced in the atmosphere by using combustion engines. Here, gas engines that use regenerative produced gases can make an important contribution. The use of methane, for example, as an energy source, already proves the performance of these engines in trucks. Methane gas can be synthesized from regenerative electricity and stored in the existing gas grid, making the gas grid an ideal existing storage facility. Through further processing, synthetic liquid fuels could also be obtained and used for existing machines. It is still unclear which clean drive solution(s) will prevail in the future. To clarify this, there are still many challenges to be solved regarding the drive of the machines. 